\title{
Author Correction: Smac mimetics and oncolytic viruses synergize in driving anticancer T-cell responses through complementary mechanisms
}

\author{
Dae-Sun Kim¹,2,3, Himika Dastidar1,2,3, Chunfen Zhang1,2, Franz J. Zemp1,2,3, Keith Lau1,2,3,4, Matthias Ernst ${ }^{1,2}$, \\ Andrea Rakic1,2,5, Saif Sikdar 1,2,3, Jahanara Rajwani 1,2, Victor Naumenko1,2,3,4, Dale R. Balce ${ }^{6}$, Ben W. Ewanchuk ${ }^{7}$, \\ Pankaj Tailor ${ }^{6}$, Robin M. Yates (1) 6,7, Craig Jenne ${ }^{3,4}$, Chris Gafuik ${ }^{1,2,3}$ \& Douglas J. Mahoney ${ }^{1,2,3,7}$
}

Correction to: Nature Communications. https://doi.org/10.1038/s41467-017-00324-x; published online 24 August 2017

The originally published version of this article contained an error in the spelling of the author Pankaj Tailor, which was incorrectly given as Pankaj Taylor. This has now been corrected in both the PDF and HTML versions of the article.

Published online: 24 May 2018

\begin{abstract}
(c) (i) Open Access This article is licensed under a Creative Commons Attribution 4.0 International License, which permits use, sharing, adaptation, distribution and (c) reproduction in any medium or format, as long as you give appropriate credit to the original author(s) and the source, provide a link to the Creative Commons license, and indicate if changes were made. The images or other third party material in this article are included in the article's Creative Commons license, unless indicated otherwise in a credit line to the material. If material is not included in the article's Creative Commons license and your intended use is not permitted by statutory regulation or exceeds the permitted use, you will need to obtain permission directly from the copyright holder. To view a copy of this license, visit http://creativecommons.org/licenses/by/4.0/.
\end{abstract}

() The Author(s) 2018

\footnotetext{
${ }^{1}$ Alberta Children's Hospital Research Institute, Calgary, AB, Canada T2N 4N1. ${ }^{2}$ Arnie Charbonneau Cancer Institute, Calgary, AB, Canada T2N 4N1.

${ }^{3}$ Department of Microbiology, Immunology and Infectious Disease, Faculty of Medicine, University of Calgary, Calgary, AB, Canada T2N 4N1. ${ }^{4}$ Snyder Institute for Chronic Disease, Calgary, AB, Canada T2N 4N1. ${ }^{5}$ Department of Medical Sciences, Faculty of Medicine, University of Calgary, Calgary, AB, Canada T2N 4N1. ${ }^{6}$ Department of Comparative Biology and Experimental Medicine, Faculty of Veterinary Medicine, University of Calgary, Calgary, Canada T2N 4N1. ${ }^{7}$ Department of Biochemistry and Molecular Biology, Faculty of Medicine, University of Calgary, Calgary, AB, Canada T2N 4N1. Correspondence and requests for materials should be addressed to D.J.M. (email: djmahone@ucalgary.ca)
} 